\title{
Recreational Drug use and Risk of HIV Infection Among Young Men Who Have Sex with men: A Cross-Sectional Study in Tianjin, China
}

\section{Changping $\mathbf{L i}$}

Tianjin Medical University

\section{Zeyang Yu}

Tianjin Medical University

\section{Yang Chen}

Tianjin Medical University

Honglu Zhang

Tianjin Medical University

\section{Huijie Huang}

Tianjin Medical University

\section{Chun Wang}

Tianjin Medical University

\section{Elissa Peixoto}

Tianjin Medical University

\section{Tingting Yao}

Tianjin Medical University

Tiantian Zhang

Tianjin Medical University

\section{Desheng Song}

Tianjin Medical University

\section{Xiaomeng Wang}

Tianjin Medical University

Jie Yang

Tianjin Shenlan Community Based Organization

\section{Yuanyuan Liu}

Tianjin Medical University

\section{Maohe Yu}

City Centter for Disease Control and Prevention, Tianjin

\section{Zhuang Cui ( $\square$ ZhuangCui417@126.com )}

Tianjin Medical University https://orcid.org/0000-0001-6495-766X 


\section{Research article}

Keywords: Young men who have sex with men, Recreational drugs, HIV, Additive interaction

Posted Date: February 1st, 2021

DOl: https://doi.org/10.21203/rs.3.rs-192111/v1

License: (c) (i) This work is licensed under a Creative Commons Attribution 4.0 International License. Read Full License 


\section{Abstract}

Background- Recreational drug use among young men who have sex with men (YMSM) was a public health issue of worldwide concern. Evidence had shown the relevance between recreational drug use and human immunodeficiency virus (HIV) infection. This study aimed to investigate the current prevalence state of recreational drug use among YMSM in Tianjin, discern the characteristics of YMSM who used recreational drugs or not and examine the interaction effect of recreational drug use and unprotected anal intercourse (UAI) on HIV infection.

Methods- In 2018, a cross-sectional study was conducted in Tianjin, China. The snowball sampling method was used to recruit YMSM. Participants were recruited from gay bars, gay bathhouses, social network sites (WeChat, QQ, gay chat website), gay apps and peer referrals. Structured questionnaires were used to collect data.

Results- A total of 1075 YMSM met the eligibility criteria and were included in the study eventually. The overall HIV prevalence was 4.3\% (46/1075). Of all the recreational drugs involved in this study (rush poppers, methamphetamine, capsule No.0), rush poppers (406/517,78.5\%) were the most popular among YMSM in Tianjin. Compared with non-drug users, drug users were more likely to have first sex earlier, be bisexual, be male sex worker (MSW), have a higher education level, seek sex partners through physical venues, engage in UAl, have sexually transmitted infection (STI), and receive HIV testing. Moreover, recreational drug use and UAI were associated with the increased risk of HIV infection [adjusted OR:3.6 (95\% Cl: $1.7-7.6)$ and 4.9 (95\% Cl: $2.2-10.4)$, respectively]. There was additive interaction of recreational drug use and UAI on HIV infection [relative excess risk due to interaction (RERI): 6.949 (95\%Cl: 0.01113.887); attributable proportion due to interaction (AP): 0.809 (95\% Cl: 0.578-1.039)].

Conclusions- Recreational drug use was common and correlated with HIV infection among YMSM in Tianjin. There was an urgent need to build novel targeted HIV prevention strategies to discern and reduce recreational drug use among YMSM in China.

\section{Introduction}

The prevalence of human immunodeficiency virus (HIV) infection had been low among the general population over the past three decades. However, the burden of HIV infection was disproportionately concentrated among men who have sex with men (MSM)[1, 2]. According to the Joint United Nations Programme on HIV/AIDS (UNAIDS) data, among Asia and the Pacific, MSM contribution to $44 \%$ of new HIV infections in 2019[3]. Additionally, evidence of global HIV infection showed that HIV infection was converging among young men who have sex with men (YMSM) [4, 5]. Compared with the older MSM, YMSM were in their sexually active period and might have more sexual activities. Moreover, owing to freshness, thrill-seeking and peer influence [6-9], they were more likely to use recreational drugs when engaging in sexual behaviors. Data from World Health Organization (WHO) also indicated that YMSM 
were more vulnerable to HIV and had a greater HIV risk than heterosexual young people or older MSM[10], which implied they were a special population to be concerned.

Recreational drug use among MSM was a public health issue of worldwide concern. Due to China's effective legal control and intensive regulations on drugs over recent years[11], the utilization rate of traditional drugs (heroin, opium) had significantly decreased. Unlike traditional drugs, the legal definitions of recreational drugs were often vague and imprecise. So these drugs were not being well controlled by relevant drug legislation[12]. There was an increase in the use of recreational drugs in China[11, 13, 14]. Using recreational drugs helped MSM deal with shame and vulnerability issues they might have from outside. Some drugs like rush popper could relax the anal sphincter, reduce anal pain and help MSM quickly expand blood vessels to reach orgasm in a short period, improving the sexual experience[15]. However, a growing body of research indicated that recreational drug use was associated with increased risk of unprotected anal intercourse (UAI)[16-18], intimate partner violence (IPV)[19], group sex[17] and HIV/sexually transmitted infection (STI)[11, 19-22]. Moreover, MSM could ensue dependent and abuse in recreational drugs after long-term continuous use [23]. In the context of HIV treatment, recreational drug using among HIV-positive individuals had been proved to be associated with non-adherence of antiretroviral treatments (ARTs)[24-26]. That meant if the HIV-positive individuals were treated with ARTs and still used recreational drugs at the same time, they would become more infectious to other individuals when engaging in sexual behaviors[17].

To date, researches on the association between recreational drug use and HIV infection among MSM were relatively common. However, analyses of the profiles among YMSM who used recreational drugs had received scant attention in the research literature. Besides, little information existed on examining the interaction effect of recreational drug use and UAI on HIV infection. The HIV prevalence of YMSM in China had significant growth over the past decade (2005-07: 2.9\%, 2008-10:5.2\%, 2011-14: 6.3\%)[27]. China was a country with traditional Confucianism as its main social values[28]. Sexual behaviors between men in China were taboo both politically and by family/cultural tradition. Although not illegal, YMSM endure stigma and discrimination by both the family and society[29, 30]. This had set obstacles to explore the behavioral characteristics of YMSM in China. However, the corresponding research was still necessary and had very important practical significance. The findings of this study should contribute to the field of proposing novel targeted prevention and intervention measures on reducing recreational drug use and HIV infection among YMSM.

\section{Methods}

\section{Recreational drugs}

Recreational drugs were also known as "club drugs". In this study, recreational drug use was defined as the use of any type of drugs (one or more) at some time before or during sexual behaviors over the past 6 months. 
The recreational drugs involved rush poppers, methamphetamine and capsule No.0. Rush poppers were aphrodisiac gas composed of volatile nitrite. Its main function was to relax the smooth muscles.

Originally, rush poppers were emergency medicine for heart disease. MSM used them to expand blood vessels and reduce the perception of pain, for the smooth muscles were also distributed around the anus. Methamphetamine, known as crystal meth, was a central nervous system stimulant and widely used as an illicit drug. It had a high potential for abuse. Capsule No.0, the main ingredient was 5-MeO-MiPT, was psychedelic in the tryptamine class. It was known for producing greater tactile, bodily, and sexual effects than other psychedelics. "Capsule No.0" was a code name among MSM in China.

\section{Research Design}

A cross-sectional study was conducted in Tianjin, China in 2018. The organizations involved in the project included US Centers for Disease Control and Prevention (CDC); National Center for AIDS/STD Control and Prevention, Chinese Center for Disease Control and prevention (NCAIDS/STD); Tianjin City $\mathrm{CDC}$ and Tianjin Shenlan Community-Based Organization (CBO).

During the implementation of the study, Tianjin City CDC and Tianjin Shenlan CBO had established a cooperative relationship of mutual assistance, complementarity and mutual benefit. Tianjin City CDC's support for the Tianjin Shenlan CBO was mainly reflected in data reporting, technical support, funds management and staff training to improve professional proficiency. Besides, Tianjin City CDC undertook data verification; provided HIV confirmation, CD4 and viral load test; supervise the implementation process and quality control.

Tianjin Shenlan CBO was a formally community-based organization that provided community-based support services (including HIV testing, counseling and psychological support) for MSM. The organization had a good influence and a high reputation among MSM in Tianjin. Therefore, staff in the organization were able to contact with MSM expediently, which facilitated the collection and authenticity of data.

\section{Participants And Data Collection}

The snowball sampling method was used to recruit YMSM. Participants were recruited from gay bars, gay bathhouses, social network sites (WeChat, QQ, gay chat website), gay apps and peer referrals. Inclusion criteria were: (1) > 16 and $\leq 24$ years old, (2) biologically male, (3) having sex with another man in the past one year, (4) able to complete investigation, (5) understanding informed consent and privacy issues.

Data were collected by trained staff of the Tianjin Shenlan CBO. The staff of the organization mostly were also MSM, so they could truly experience what the participants underwent, which would be a benefit for smooth unhindered communication with participants. Participants were invited to the Tianjin Shenlan Loading [MathJax]/jax/output/CommonHTML/jax.js 
CBO's public health advisory service center for community-based support services. When participants came to the public health advisory service center for counseling or testing, experienced staff would conduct a face-to-face interview with participants. During this period, a structured questionnaire was completed by the participants under the guidance of the staff.

The content of the questionnaire included, (1) Socio-demographics data: age, self-reported sexual orientation, ethnicity, educational level, marital status, occupations, the local residence time in Tianjin. (2) Sexual behaviors: age of sexual debut, UAI over the past 6 months, routes to seek sex partners, awareness of HIV-related knowledge, any STI over the past 12 months, HIV testing history over the past 12 months. (3) Info of recreational drug use over the past 6 months.

\section{Hiv Laboratory Test}

Before testing, YMSM would choose to collect blood or saliva. Patrons' oral mucosal exudate test (Mano Bio-Pharmaceutical Co., Ltd, Beijing, China) was used for the former and a blood rapid detection reagent (Wan Fu Biotechnology Co., Ltd, Guangzhou, China) for the latter. In addition, $5 \mathrm{ml}$ of blood sample was collected from those who get any positive tests above. Then, the blood sample was sent to Tianjin CDC to perform enzyme-linked immunosorbent (ELISA; Wan Tai Biological Pharmaceutical Co., Ltd, Beijing, China). HIV infection was by confirmed Western blot (WB) assay (MP Biomedical Asia Pacific Pte Ltd, Singapore).

\section{Statistical Methods}

Category variables were described by frequencies and proportions. For the general demographic characteristics, differences were calculated using Pearson's chi-squared test or Fisher's exact test. The univariate and multivariate logistic regression model was performed to evaluate (1) the associations between recreational drug use and each factor (2) risk of recreational drug use and UAI on HIV infection. Variables for the multivariate model were based on the results of univariate analysis. Variables with a $P$ value less than 0.1 were selected into the multivariate model. Odds ratios (OR), adjusted odds ratios (aOR) and their $95 \% \mathrm{Cl}$ of the variables were estimated. Stratified analysis among participants engaging in UAI or not engaging in UAI were performed to check the consistency of ORs of recreational drug use for the risk of HIV infection across subgroups. For the model where data separation occurred and the maximum likelihood method failed to converge, the firth statement was added into SAS logistic model procedure to make it converge.

The additive interaction of recreational drug use and UAI on HIV infection risk was tested to explore possible enhancing effects of drug use on UAl-associated risk of HIV infection. Additive interaction was estimated using indicators included relative excess risk due to interaction (RERI), attributable proportion due to interaction (AP), and synergy index (S). If there was significant additive interaction, the $95 \% \mathrm{Cl}$ of Loading [MathJax]/jax/output/CommonHTML/jax.js of $\mathrm{S}$ would not contain 1. i.e., recreational drug use enhanced 
the risk of UAI on HIV infection. All the data analyses were performed in SAS version 9.4 (SAS Institute Inc., Cary, NC).

\section{Results}

\section{Characteristics of the participants}

A total of 1075 YMSM met the eligibility criteria and were included in the study eventually. Confirmed by the laboratory test, 46 participants were HIV-positive and the overall HIV prevalence was $4.3 \%(46 / 1075)$. Among all the participants, the mean age was $21.5 \pm 1.7$ years (ranging from 16 to 24 years); $98.7 \%$ were homosexuals; $97.6 \%$ were ethnically Han; $99.3 \%$ were unmarried; $46.7 \%$ were students; $59.2 \%$ had a university degree or above; $48.1 \%$ used recreational drugs (at least one type); $84.7 \%$ had been lived in Tianjin for more than 2 years; $82.7 \%$ were seeking sexual partners through the internet; $97.3 \%$ had a good understanding of HIV-related knowledge; $49.6 \%$ engaged in UAI over past 6 months, $2.9 \%$ had STI over past 12 months and $70.6 \%$ received HIV testing over past 12 months (Table 1 ). 
Table 1

Characteristics of demographics data, sexual behaviors, recreational drug use of the YMSM in Tianjin, China.

\begin{tabular}{|c|c|c|c|c|}
\hline \multirow[t]{3}{*}{ Variables } & \multirow{3}{*}{$\begin{array}{l}\text { Total } \\
(\mathrm{N}, \%)\end{array}$} & \multicolumn{2}{|l|}{ HIV Infection } & \multirow[t]{3}{*}{$P^{a}$} \\
\hline & & No & Yes & \\
\hline & & $(\mathrm{N}, \%)$ & $(\mathrm{N}, \%)$ & \\
\hline Age & & & & 0.047 \\
\hline $16 \sim 18$ & $59(5.5)$ & $53(5.2)$ & $6(13.0)$ & \\
\hline $19 \sim 21$ & $436(40.5)$ & $416(40.4)$ & $20(43.5)$ & \\
\hline $22 \sim 24$ & $580(54.0)$ & $560(54.4)$ & $20(43.5)$ & \\
\hline Age of sexual debut & & & & 0.002 \\
\hline$<18$ & $374(34.8)$ & $348(33.8)$ & $26(56.5)$ & \\
\hline$>18$ & $701(65.2)$ & $681(66.2)$ & $20(43.5)$ & \\
\hline Ethnicity & & & & 0.095 \\
\hline Han & 1049(97.6) & 1006(97.8) & $43(93.5)$ & \\
\hline Others & $26(2.4)$ & $23(2.2)$ & $3(6.5)$ & \\
\hline Sex orientation & & & & 0.955 \\
\hline Homosexual & 1030(95.8) & $986(95.8)$ & $44(95.7)$ & \\
\hline Bisexual & $45(4.2)$ & $43(4.2)$ & $2(4.3)$ & \\
\hline Occupations & & & & 0.345 \\
\hline Others & 212(19.7) & $207(20.1)$ & $5(10.9)$ & \\
\hline Service industry & $313(29.1)$ & 297(28.9) & 16(34. 8) & \\
\hline Student & $502(46.7)$ & $478(46.5)$ & $24(52.1)$ & \\
\hline$M_{S W}^{b}$ & $48(4.5)$ & $47(4.5)$ & $1(2.2)$ & \\
\hline Marital status & & & & 0.735 \\
\hline Unmarried & 1068(99.3) & 1022(99.3) & $46(100.0)$ & \\
\hline Married & $7(0.7)$ & $7(0.7)$ & $0(0.0)$ & \\
\hline Education & & & & 0.401 \\
\hline Primary & $51(4.8)$ & $48(4.7)$ & $3(6.5)$ & \\
\hline Secondarv & $385(35.8)$ & $365(35.4)$ & $20(43.5)$ & \\
\hline
\end{tabular}




\begin{tabular}{|c|c|c|c|c|}
\hline \multirow[t]{3}{*}{ Variables } & \multirow{3}{*}{$\begin{array}{l}\text { Total } \\
(\mathrm{N}, \%)\end{array}$} & \multicolumn{2}{|l|}{ HIV Infection } & \multirow[t]{3}{*}{$P^{a}$} \\
\hline & & No & Yes & \\
\hline & & $(\mathrm{N}, \%)$ & $(\mathrm{N}, \%)$ & \\
\hline University & 639(59.4) & $616(59.9)$ & $23(50.0)$ & \\
\hline Recreational drug & & & & 0.001 \\
\hline No & $558(51.9)$ & $548(53.3)$ & $10(21.7)$ & \\
\hline Yes & $517(48.1)$ & $481(46.7)$ & $36(78.3)$ & \\
\hline Residence time & & & & 0.078 \\
\hline$<1$ year & $90(8.4)$ & $82(8.0)$ & $8(17.4)$ & \\
\hline $1 \sim 2$ years & $75(7.0)$ & $72(7.0)$ & $3(6.5)$ & \\
\hline$>2$ years & $910(84.6)$ & $875(85.0)$ & $35(76.1)$ & \\
\hline Partner-seeking ${ }^{c}$ & & & & 0.238 \\
\hline Physical venues & 186(17.3) & 181(17.6) & $5(10.9)$ & \\
\hline Internet-based & $889(82.7)$ & $848(82.4)$ & $41(89.1)$ & \\
\hline Knowledge $^{d}$ & & & & 0.276 \\
\hline Unclear & $29(2.7)$ & $29(2.8)$ & $0(0.0)$ & \\
\hline Knowing & 1046(97.3) & $1000(97.2)$ & $46(100.0)$ & \\
\hline UAl $^{e}$ & & & & 0.001 \\
\hline No & $542(50.4)$ & $533(51.8)$ & $9(19.6)$ & \\
\hline Yes & $533(49.6)$ & $496(48.2)$ & $37(80.4)$ & \\
\hline STIf & & & & 0.252 \\
\hline No & 1044(97.1) & $998(97.0)$ & $46(100.0)$ & \\
\hline Yes & $31(2.9)$ & $31(3.0)$ & $0(0.0)$ & \\
\hline Testing historyg & & & & 0.411 \\
\hline No & $316(29.4)$ & $300(29.2)$ & $16(34.7)$ & \\
\hline Yes & 759(70.6) & $729(70.8)$ & $30(65.3)$ & \\
\hline Total & $1075(100.0)$ & 1029(100.0) & $46(100.0)$ & \\
\hline
\end{tabular}




\begin{tabular}{|l|l|}
\hline Variables & \multicolumn{1}{|c|}{ Total } \\
\cline { 2 - 3 } & $(\mathrm{N}, \%)$ \\
\hline
\end{tabular}

\section{Types Of Recreational Drugs Used By Ymsm}

In this study, 517 YMSM reported using at least one type of recreational drug over the past 6 months. The proportion of recreational drug use was $48.1 \%$ (517/1075). Among drug users, 411 (79.5\%) used only one type of drug while 106 (20.5\%) were polydrug users. Rush poppers (406/517,78.5\%) were the most commonly used recreational drug (Table 2). 
Table 2

Types of recreational drugs used by YMSM.

\begin{tabular}{|c|c|c|c|c|c|}
\hline \multirow{3}{*}{$\begin{array}{l}\text { Use Recreational } \\
\text { Drug }\end{array}$} & \multirow[t]{3}{*}{ Recreational drug types } & \multicolumn{2}{|c|}{ HIV Infection } & \multirow{3}{*}{$\begin{array}{l}\text { Total } \\
(\mathrm{N}, \%)\end{array}$} & \\
\hline & & No & Yes & & \\
\hline & & $(\mathrm{N}, \%)$ & $(\mathrm{N}, \%)$ & & \\
\hline \multirow{3}{*}{$\begin{array}{l}\text { YMSM who used } \\
\text { one type of drug }\end{array}$} & Rush poppers & $383(79.6)$ & $23(63.9)$ & $406(78.5)$ & \multirow[t]{3}{*}{$411(79.5$} \\
\hline & Capsule No.0 & $3(0.6)$ & $0(0.0)$ & $3(0.6)$ & \\
\hline & Methamphetamine & $2(0.4)$ & $0(0.0)$ & $2(0.4)$ & \\
\hline \multirow{7}{*}{$\begin{array}{l}\text { YMSM who were } \\
\text { polydrug users }\end{array}$} & Methamphetamine \& & $40(8.4)$ & $4(11.1)$ & $44(8.5)$ & \multirow[t]{6}{*}{$106(20.5)$} \\
\hline & Rush poppers \& & & & & \\
\hline & Capsule No.0 & & & & \\
\hline & Rush poppers \& & $35(7.3)$ & $9(25.0)$ & $44(8.5)$ & \\
\hline & Capsule No.0 & & & & \\
\hline & $\begin{array}{l}\text { Methamphetamine \& } \\
\text { Rush poppers }\end{array}$ & $18(3.7)$ & $0(0.0)$ & $18(3.5)$ & \\
\hline & Total & $481(100.0)$ & $36(100.0)$ & $517(100.0)$ & \\
\hline
\end{tabular}

\section{Characteristics Of Ymsm Who Used Recreational Drugs Or Not}

Among drug users and non-drug users, the HIV prevalence were 7.0\% (36/517) and 1.8\% (10/558), respectively $(P=0.001)$. Univariate analysis showed age of sexual debut, sex orientation, occupations, routes to seek sex partners, HIV-related knowledge, STI history and HIV testing history were statistical significance between the two categories (Table 3). 
Table 3

Characteristics of YMSM who used recreational drugs or not in Tianjin, China.

\begin{tabular}{|c|c|c|c|c|c|c|}
\hline \multirow[t]{3}{*}{ Variables } & \multicolumn{2}{|l|}{ Drug Use } & \multirow[t]{3}{*}{$O R(95 \% C l)$} & \multirow[t]{3}{*}{$P$} & \multirow[t]{3}{*}{$a O R^{a}(95 \% C l)$} & \multirow[t]{3}{*}{$P$} \\
\hline & No & Yes & & & & \\
\hline & $(\mathrm{N}, \%)$ & $(\mathrm{N}, \%)$ & & & & \\
\hline \multicolumn{7}{|l|}{ Age } \\
\hline $16 \sim 18$ & $27(4.8)$ & $32(6.2)$ & REF & & & \\
\hline $19 \sim 21$ & $237(42.5)$ & 199(38.5) & $0.7(0.4,1.2)$ & 0.215 & & \\
\hline $22 \sim 24$ & $294(52.7)$ & $286(55.3)$ & $0.8(0.4,1.4)$ & 0.471 & & \\
\hline \multicolumn{7}{|c|}{ Age of sexual debut } \\
\hline$<18$ & $151(27.1)$ & $223(43.1)$ & REF & & REF & \\
\hline$>18$ & 407(72.9) & $294(56.9)$ & $0.5(0.4,0.6)$ & 0.001 & $0.4(0.3,0.6)$ & 0.001 \\
\hline \multicolumn{7}{|l|}{ Ethnicity } \\
\hline Han & $549(98.4)$ & $500(96.7)$ & REF & & REF & \\
\hline Others & $9(1.6)$ & $17(3.3)$ & $2.1(0.9,4.7)$ & 0.080 & $1.9(0.8,4.7)$ & 0.123 \\
\hline \multicolumn{7}{|l|}{ Sex orientation } \\
\hline Homosexual & $543(97.3)$ & $487(94.2)$ & REF & & REF & \\
\hline Bisexual & $15(2.7)$ & $30(5.8)$ & $2.2(1.1,4.2)$ & 0.012 & $2.1(1.1,4.5)$ & 0.031 \\
\hline \multicolumn{7}{|l|}{ Occupations } \\
\hline Others & $92(16.5)$ & $120(23.2)$ & REF & & REF & \\
\hline Service industry & $149(26.7)$ & 164(31.7) & $0.8(0.5,1.2)$ & 0.342 & $1.1(0.7,1.7)$ & 0.522 \\
\hline Student & $306(54.8)$ & 196(37.9) & $0.5(0.4,0.7)$ & 0.001 & $0.5(0.3,0.8)$ & 0.002 \\
\hline MSW & $11(2.0)$ & $37(7.2)$ & $2.6(1.2,5.3)$ & 0.011 & $2.7(1.2,6.2)$ & 0.012 \\
\hline \multicolumn{7}{|l|}{ Marital status } \\
\hline Unmarried & $556(99.6)$ & $512(99.0)$ & REF & & & \\
\hline Married & $2(0.4)$ & $5(1.0)$ & $2.7(0.5,14.0)$ & 0.234 & & \\
\hline \multicolumn{7}{|l|}{ Education } \\
\hline Primary & $28(5.0)$ & $23(4.4)$ & REF & & REF & \\
\hline
\end{tabular}




\begin{tabular}{|c|c|c|c|c|c|c|}
\hline \multirow[t]{3}{*}{ Variables } & \multicolumn{2}{|l|}{ Drug Use } & \multirow[t]{3}{*}{ OR(95\% Cl) } & \multirow[t]{3}{*}{$P$} & \multirow[t]{3}{*}{$\operatorname{aOR}(95 \% \mathrm{Cl})$} & \multirow[t]{3}{*}{$P$} \\
\hline & No & Yes & & & & \\
\hline & $(\mathrm{N}, \%)$ & $(\mathrm{N}, \%)$ & & & & \\
\hline Secondary & 167(29.9) & $218(42.2)$ & $1.5(0.8,2.9)$ & 0.122 & $2.2(1.2,4.3)$ & 0.015 \\
\hline University & $363(65.1)$ & $276(53.4)$ & $0.9(0.5,1.6)$ & 0.791 & $2.3(1.1,4.5)$ & 0.019 \\
\hline \multicolumn{7}{|l|}{ Residence time } \\
\hline$<1$ year & $47(8.4)$ & $43(8.3)$ & REF & & REF & \\
\hline $1 \sim 2$ years & $49(8.8)$ & $26(5.0)$ & $0.5(0.3,1.1)$ & 0.090 & $1.1(0.5,2.1)$ & 0.822 \\
\hline$>2$ years & $462(82.8)$ & $448(86.7)$ & $1.1(0.6,1.6)$ & 0.792 & $1.3(0.7,2.2)$ & 0.297 \\
\hline \multicolumn{7}{|l|}{ Partner-seeking } \\
\hline Physical venues & $69(12.4)$ & $117(22.6)$ & REF & & REF & \\
\hline Internet-based & 489(87.6) & $400(77.4)$ & $0.5(0.3,0.6)$ & 0.001 & $0.5(0.3,0.8)$ & 0.001 \\
\hline \multicolumn{7}{|l|}{ Knowledge } \\
\hline Unclear & $21(3.8)$ & $8(1.5)$ & REF & & REF & \\
\hline Knowing & $537(96.2)$ & $509(98.5)$ & $2.4(1.1,5.6)$ & 0.030 & $1.9(0.8,4.6)$ & 0.156 \\
\hline \multicolumn{7}{|l|}{ UAl } \\
\hline No & $289(51.8)$ & $253(48.9)$ & REF & & REF & \\
\hline Yes & $269(48.2)$ & $264(51.1)$ & $1.1(0.8,1.4)$ & 0.349 & $1.7(1.3,2.2)$ & 0.001 \\
\hline \multicolumn{7}{|l|}{ STI } \\
\hline No & $550(98.6)$ & 494(95.6) & REF & & REF & \\
\hline Yes & $8(1.4)$ & $23(4.4)$ & $3.2(1.4,7.2)$ & 0.005 & $2.4(1.1,5.7)$ & 0.039 \\
\hline \multicolumn{7}{|l|}{ Testing history } \\
\hline No & $209(37.5)$ & $107(20.7)$ & REF & & REF & \\
\hline Yes & $349(62.5)$ & $410(79.3)$ & $2 \cdot 3(1.7,3.1)$ & 0.001 & $2.4(1.8,3.3)$ & 0.001 \\
\hline Total & $558(100.0)$ & $517(100.0)$ & & & & \\
\hline
\end{tabular}

According to multivariate logistic regression result, drug users were more likely to be bisexual (aOR: 2.1, Loading [MathJax]/jax/output/CommonHTML/jax.js 
(secondary, aOR: $2.2,95 \% \mathrm{Cl}$ : 1.2-4.3; or university, aOR: $2.3,95 \% \mathrm{Cl}: 1.1-4.5)$, engage in UAI (aOR: 1.7, 95\%Cl: 1.3-2.2), have STI (aOR: 2.4, 95\% Cl: $1.1-5.7$ ) and receive HIV testing before (aOR: $2.4,95 \% \mathrm{Cl}$ : 1.8-3.3). While non-drug users were more likely to have first sex after adulthood (aOR: $0.4,95 \% \mathrm{Cl}: 0.3-$ $0.6)$, be student (aOR: $0.5,95 \% \mathrm{Cl}: 0.3-0.8)$ and seek sex partners through the internet (aOR: $0.5,95 \% \mathrm{Cl}$ : $0.3-0.8)$.

\section{Recreational Drug Use And Uai On Hiv Infection Risk}

Recreational drug use was associated with increased risk of HIV infection in univariable analysis and multivariable analysis (OR: 4.1, 95\%Cl: 2.0-8.3; aOR: 3.6, 95\%Cl: 1.7-7.6). UAl was associated with an increased risk of HIV infection in univariable analysis and multivariable analysis (OR: 4.4, 95\%Cl: 2.1-9.2; aOR: 4.9, 95\% Cl: 2.2-10.4) (Table 4). 
Table 4

ORs of recreational drug use and UAI for the risk of HIV infection.

HIV Infection ( $\mathrm{N}, \%) \quad$ OR $(95 \% \mathrm{Cl})$

$\operatorname{aOR}^{a}(95 \% \mathrm{Cl})$

Independent Models

Recreational drug use

No

10(21.7)

REF REF

Yes

$36(78.3)$

$4.1(2.0,8.3)$

$3.6(1.7,7.6)$

UAI

No

$9(19.6)$

REF

REF

Yes

37(80.4)

4.4(2.1,9.2)

$4.9(2.2,10.4)$

\section{Subgroup Analysis}

Engage in UAI

Recreational drug use

No

$6(16.2)$

REF

REF

Yes

31(83.8)

$5.8(2.3,14.2)$

$5.5(2.2,13.7)$

Not engage in UAI

Recreational drug use

No

$4(44.4)$

REF

REF

Yes

5(55.6)

$1.4(0.4,5.4)$

$1.1(0.3,4.3)$

Additive Interaction Model

Not engage in UAI and non-drug user

$4(8.7)$

REF

REF

Not engage in UAI and drug user

$5(10.9)$

$1.4(0.4,5.4)$

$1.1(0.3,4.3)$

Engage in UAl and non-drug user

$6(13.0)$

$1.6(0.5,5.8)$

$1.5(0.4,5.4)$

Engage in UAI and drug user

$31(67.4)$

$9.4(3.2,27.2)$

$8.5(2.9,24.8)$

a. aOR was the OR of adjusting for other variables (age, age of sexual debut, ethnicity and residence time).

\section{Subgroup analysis of recreational drug use on HIV infection risk}

In the subgroup analyses, among YMSM who engaged in UAI, the multivariable aOR of recreational drug use on HIV infection was increased to 5.5 (95\% Cl: 2.2-13.7) while the aOR using the entire study 
population was 3.6 (95\% Cl: 1.7-7.6) (Table 4). Among YMSM who did not engage in UAl, the multivariable aOR of recreational drug use on HIV infection was attenuated to 1.1 (95\% Cl: 0.3-4.3).

\section{Additive interaction between recreational drug use and UAI on HIV infection risk}

From the results of the subgroup analysis, we inferred that there might be an interaction between recreational drug use and UAI. Making the non-UAI and non-drug user group as the reference, recreational drug use increased the aOR of UAI on HIV infection from 1.5 (95\% Cl: $0.4-5.4)$ to 8.5 (95\% Cl: $2.9-24.8)$ with a significant additive interaction (RERI: $6.949,95 \% \mathrm{Cl}$ : 0.011-13.887; AP: 0.809, 95\% Cl: 0.578-1.039) (Table 5).

Table 5

Additive interaction of recreational drug use and UAI on HIV infection risk

\section{Measures of Additive Interaction}

Estimate $^{\mathrm{a}}(95 \% \mathrm{Cl})$

Multivariable analysis ${ }^{b}$

\section{RERIC}

$$
\text { AP }
$$

$S$
6.949(0.011,13.887)

$0.809(0.578,1.039)$

$11.786(0.244,569.832)$

a. Statistically significant, with RERI $>0, A P>0$, or $S>1$ indicating significant additive interaction.

b. aOR was the OR of adjusting for other variables (age, age of sexual debut, ethnicity and residence time).

c. RERI, relative excess risk due to interaction; AP, attributable proportion due to interaction; S, synergy inde

\section{Discussion}

The proportion of recreational drugs used among YMSM in this study was 48.1\% (517/1075), higher than studies among MSM in other cities of China: Hangzhou[22], 18.2\% (101/555); Shenzhen[11], 12.7\% (245/1935); Changsha[21], 21.4\% (177/826); Shenyang[31], 23.2\% (145/625) and Sichuan[32], 27.6\% (310/1122). Using recreational drugs such as rush poppers might generate "cognitive escape", which was characterized by avoidance from thought related to HIV infection. Consequently, YMSM were more likely to engage in sexual risk behaviors like UAl, group sex even IPV and could potentiate further HIVtransmissions in the community[33].

In this study, drug users might have first sex earlier. YMSM were in the period of transition from adolescence to adulthood. Their mind was not mature enough. Premature sexual behaviors at this period had a greater impact on their substance use after adulthood[34].Compared with other groups, students might less likely to use recreational drugs and MSW were more likely to use drugs. Because of the Loading [MathJax]/jax/output/CommonHTML/jax.js use recreational drugs more frequently[35]. Drug users were 
more likely to have higher education. The impact of education levels on drug use mostly laid in extensive social networking and availability for drugs[7]. One study also found that it was difficult for those with university education levels to attain an appropriate support network for avoiding recreational drug use, thus leading to drug use[36]. Our data showed that drug-users were more likely to be bisexual. A YMSM was bisexual meant that YMSM had more sexual partners than those who were homosexual. Meanwhile, faced discrimination from both heterosexual and homosexual individuals, bisexual YMSM might be more likely to use substances before sex, because they may rely on substances to cope with stigma. But it remained unclear if bisexual YMSM were more or less likely to use substances before sex with different types of partners[37].

In this study, YMSM using recreational drugs were more likely to find sexual partners based on physical venues (gay bars, parks, and gay bathhouses). YMSM finding sexual partners through the internet-based route accounted for a large proportion $(889 / 1075,82.7 \%)$, which was consistent with the findings in China[38] and in the United States[39-41]. The proportion of recreational drugs used among YMSM seeking sexual partners through the internet-based route was $45 \%$ (400/889). However, the proportion of YMSM using recreational drugs who sought sex partners through physical venues was much higher $(117 / 186,62.9 \%)$. As another name for recreational drugs was "club drug", it was originally used in physical venues (parties, clubs). We speculated that the use of recreational drugs symbolized the trust and intimacy between YMSM. The relationship between YMSM seeking sexual partners based on physical venues might be more stable, and this sensation would prompt YMSM to use recreational drugs to increase sexual experience[17]. Due to anonymity and the instability of the relationship, the proportion of recreational drug use might decline among YMSM who sought sexual partners based on the network.

Recreational drug use and UAI had been proved to be the independent risk factors on HIV infection in numerous studies. Moreover, our study found that there was an additive interactive effect between recreational drug use and UAI on HIV infection risk, with important public health implications.

Recreational drug use amplified the effect of UAI on HIV infection risk to further increase the prevalence of HIV. This provided a hint for future HIV prevention, that is, reducing the occurrence of UAI and the risk of HIV infection by reducing the use of recreational drugs.

The results showed that drug users were more likely to have been tested for HIV in the past. This might be the result of increasing scope of relevant knowledge dissemination as China continued to improve HIV prevention. YMSM no longer avoided HIV testing, and their health awareness had also been continuously improved. They were willing to know their HIV infection status, which prompted the emergence of detection behaviors. Some studies had also pointed out that the feeling of guilt and the fear of HIV infection caused by conducting high-risk sexual behaviors would also prompt the detection of HIV[42, 43]. One other study suggested that social apps might be leveraged to promote HIV testing among YMSM[39]. Regardless of the reason for detection, prompting the YMSM to conduct regular testing was a key step in controlling the spread of HIV. This was also a positive factor found in this study and was closely related to China's investment in HIV prevention and control. 
The Important aspect of future HIV prevention and control should focus on continuing to expand the promotion of HIV prevention, eliminate the society's bad perception of HIV, and reduce the stigma of YMSM. In addition, in the analysis of the types of recreational drugs, we found that rush was used at the highest frequency, which was consistent with other studies[15, 21, 44]. Therefore, it was necessary to proactively develop control and intervention programs that aimed at drug use among YMSM in China. This suggested that the management should improve the legal system for the prevention and control of recreational drugs and strengthen the control of distribution channels.

This research has several limitations. First, in this study, the snowball sampling method was used to recruit participants, which may have certain tendentiousness. However, we recruited participants in a variety of ways (gay bars, gay bathhouses, social network sites, gay apps and peer referrals) to increase the representativeness. Second, the cross-sectional study design prevented us from making causal inferences about recreational drug use and HIV infection. Hence longitudinal investigations were needed to understand the association between them. Further, our data collection adopted a real-name registration system (ID card number, mobile phone number and fingerprint information were involved). Due to the privacy of some questions (such as whether you had ever had STI), the participants might have concealed the actual situation which may result in social expectation bias. We conducted an interviewstyle questionnaire collection to avoid this. Besides, all staff had received professional training to ensure the authenticity of the data.

\section{Abbreviations}

MSM: men who have sex with men; YMSM: young men who have sex with men; HIV: Human immunodeficiency virus; WHO: World Health Organization; UNAIDS: United Nations Programme on HIV/AIDS; STI: sexually transmitted infection; ARTs: antiretroviral treatments; IPV: intimate partner violence; UAl: unprotected anal intercourse; CDC: Centers for Disease Control and Prevention; CBO: Community-Based Organization; RERI: relative excess risk due to interaction; AP: attributable proportion due to interaction; S: synergy index; OR: odds ratio; AOR: adjusted odds ratio.

\section{Declarations}

\section{Ethics approval and consent to participate}

This study was reviewed and approved by the Institutional Review Board of the National Center for AIDS/STD Control and Prevention, China CDC [IRB approve number: X130205267] and sponsored by the President's Emergency Plan for AIDS Relief (PEPFAR). All participants have signed an informed consent form before the study.

\section{Consent for publication}

Not applicable. 


\section{Availability of data and materials}

Not applicable.

\section{Competing interests}

The authors declare that they have no competing interests

\section{Funding}

This work was supported by Outcome Evaluation of the Tianjin Bathhouse-based Health Center Program, 2011-2017, PEPFAR (President's Emergency Plan For Aids Relief, PEPFAR, USA), [NU2GGH001153] and The Humanities and Social Science Fund of the Ministry of Education, China, [20YJAZH021].

\section{Authors' contributions}

Changping Li, Zhuang Cui, Zeyang Yu, Yuanyuan Liu, and Jun Ma contributed to the research ideas of the study. Changping Li, Zhuang Cui, Huijie Huang, Tiantian Zhang, Tingting Yao, Desheng Song, Yang Chen, and Elissa Peixoto contributed to the development of the study. Maohe Yu and Jie Yang collected the data. Huijie Huang, Honglu Zhang, Chun Wang, and Xiaomeng Wang managed the data. Changping Li and Zeyang Yu analyzed the data and wrote the manuscript. Zhuang Cui revised the paper.

\section{Acknowledgments}

All authors expressed special thanks to US Centers for Disease Control and Prevention; National Center for AIDS/STD Control and Prevention, Chinese Center for Disease Control and prevention; Tianjin City $\mathrm{CDC}$ and Tianjin Shenlan Community-Based Organization.

\section{References}

1. Suguimoto SP, Techasrivichien T, Musumari PM, El-saaidi C, Lukhele BW, Ono-Kihara M, Kihara M. Changing patterns of HIV epidemic in 30 years in East Asia. Curr HIV/AIDS Rep. 2014;11(2):134-45.

2. Zhang K-L, Detels R, Liao S, Cohen M, Yu D-B. China's HIV/AIDS epidemic: continuing challenges. Lancet. 2008;372(9652):1791-3.

3. 2020: Seizing the moment - Tackling entrenched inequalities to end epidemics. 2020, Global Aids Update.

4. Beyrer C, Baral SD, Collins C, Richardson ET, Sullivan PS, Sanchez J, Trapence G, Katabira E, Kazatchkine M, Ryan O, et al. The global response to HIV in men who have sex with men. Lancet. 2016;388(10040):198-206.

5. McLaughlin K. HIV infections are spiking among young gay Chinese. Science. 2017;355(6332):1359.

6. Kecojevic A, Corliss HL, Lankenau SE. Motivations for prescription drug misuse among young men who have sex with men (YMSM) in Philadelphia. Int J Drug Policy. 2015;26(8):764-71. 
7. Janulis $P$, Birkett $M$, Phillips li G, Mustanski B. Not getting high with a little help from your friends: Social versus drug network correlates of marijuana use among YMSM. Addict Behav. 2019;92:1805.

8. Newcomb ME, Ryan DT, Greene GJ, Garofalo R, Mustanski B. Prevalence and patterns of smoking, alcohol use, and illicit drug use in young men who have sex with men. Drug Alcohol Depend. 2014;141:65-71.

9. Parsons JT, Starks TJ. Drug use and sexual arrangements among gay couples: frequency, interdependence, and associations with sexual risk. Arch Sex Behav. 2014;43(1):89-98.

10. HIV and young men who have sex with men. 2015, World Health Organization.

11. Duan C, Wei L, Cai Y, Chen L, Yang Z, Tan W, Gan Y, Au WW, Zhao J. Recreational drug use and risk of HIV infection among men who have sex with men: A cross-sectional study in Shenzhen, China. Drug Alcohol Depend. 2017;181:30-6.

12. Deluca P, Davey Z, Corazza O, Di Furia L, Farre M, Flesland LH, Mannonen M, Majava A, Peltoniemi T, Pasinetti $M$, et al. Identifying emerging trends in recreational drug use; outcomes from the Psychonaut Web Mapping Project. Prog Neuropsychopharmacol Biol Psychiatry. 2012;39(2):221-6.

13. Ding $Y, H e N$, Detels R. Circumstances of initiation into new-type drug use among adults in Shanghai: are there differences by types of first new-type drug used? Drug Alcohol Depend. 2013;131(3):27883.

14. Ding Y, He N, Detels R. Adolescent Sexual Debut and Initiation into New-Type Drug Use among a Sample of Young Adults. J Psychoactive Drugs. 2015;47(3):182-6.

15. Zhu ZP, Zhang M, Xu YY, Xu WJ, Liu L, Wu SS, Guo L, Li X. Cross-sectional surveys on the use of recreational drug nitrous-acid-ester rush-poppers in men who have sex with men, Nanjing. Zhonghua liu xing bing xue za zhi = Zhonghua liuxingbingxue zazhi 2017, 38(2):189-193.

16. Stueve A, O'Donnell L, Duran R, San Doval A, Geier J. Being high and taking sexual risks: findings from a multisite survey of urban young men who have sex with men. AIDS Educ Prev. 2002;14(6):482-95.

17. Kirby T, Thornber-Dunwell M. High-risk drug practices tighten grip on London gay scene. The Lancet. 2013;381(9861):101-2.

18. Ding Y, He N, Zhu W, Detels R. Sexual risk behaviors among club drug users in Shanghai, China: prevalence and correlates. AIDS Behav. 2013;17(7):2439-49.

19. Li Y, Baker JJ, Korostyshevskiy VR, Slack RS, Plankey MW. The association of intimate partner violence, recreational drug use with HIV seroprevalence among MSM. AIDS Behav. 2012;16(3):4918.

20. Mansergh G, Flores S, Koblin B, Hudson S, McKirnan D, Colfax GN. Alcohol and drug use in the context of anal sex and other factors associated with sexually transmitted infections: results from a multi-city study of high-risk men who have sex with men in the USA. Sex Transm Infect. 2008;84(6):509-11. 
21. Chen X, Li X, Zheng J, Zhao J, He J, Zhang G, Tang X. Club Drugs and HIV/STD Infection: An Exploratory Analysis among Men Who Have Sex with Men in Changsha, China. PloS one. 2015;10(5):e0126320.

22. He L, Pan X, Wang N, Yang J, Jiang J, Luo Y, Zhang X, Li X. New types of drug use and risks of drug use among men who have sex with men: a cross-sectional study in Hangzhou, China. BMC Infect Dis. 2018;18(1):182.

23. Bracchi M, Stuart D, Castles R, Khoo S, Back D, Boffito M: Increasing use of 'party drugs' in people living with HIV on antiretrovirals: a concern for patient safety. AIDS (London, England) 2015, 29(13):1585-1592.

24. Daskalopoulou M, Rodger AJ, Phillips AN, Speakman A, Lampe FC. Prevalence of recreational drug use is indiscriminate across antiretroviral regimens of differing drug-drug interactions among MSM. AIDS. 2016;30(5):810-2.

25. Hinkin CH, Barclay TR, Castellon SA, Levine AJ, Durvasula RS, Marion SD, Myers HF, Longshore D. Drug use and medication adherence among HIV-1 infected individuals. AIDS Behav. 2007;11(2):18594.

26. Hicks PL, Mulvey KP, Chander G, Fleishman JA, Josephs JS, Korthuis PT, Hellinger J, Gaist P, Gebo KA. The impact of illicit drug use and substance abuse treatment on adherence to HAART. AIDS care. 2007;19(9):1134-40.

27. Cao Y, Meng XY, Weng H, Peng MJ, Yan H, Li SY: Prevalence of AIDS-related sexual behaviors and HIV infection status in young men who have sex with men in China: a Meta-analysis. Zhonghua liu xing bing xue za zhi = Zhonghua liuxingbingxue zazhi 2016, 37(7):1021-1027.

28. Liu H, Liu H, Cai Y, Rhodes AG, Hong F. Money boys, HIV risks, and the associations between norms and safer sex: a respondent-driven sampling study in Shenzhen, China. AIDS Behav. 2009;13(4):652-62.

29. Wong WC, Zhang J, Wu SC, Kong TSK, Ling DCY. The HIV related risks among men having sex with men in rural Yunnan, China: a qualitative study. Sex Transm Infect. 2006;82(2):127-30.

30. Liu H, Yang H, Li X, Wang N, Liu H, Wang B, Zhang L, Wang Q, Stanton B. Men who have sex with men and human immunodeficiency virus/sexually transmitted disease control in China. Sex Transm Dis. 2006;33(2):68-76.

31. Xu JJ, Qian HZ, Chu ZX, Zhang J, Hu QH, Jiang YJ, Geng WQ, Zhang CM, Shang H. Recreational drug use among Chinese men who have sex with men: a risky combination with unprotected sex for acquiring HIV infection. Biomed Res Int. 2014;2014:725361.

32. Dai Y, Musumari PM, Chen H, Huang Y, Techasrivichien T, Suguimoto SP, Zhang J, Ono-Kihara M, Kihara M. Recreational Drug Use, Polydrug Use and Sexual Behaviors Among Men Who Have Sex With Men in Southwestern China: A Cross-Sectional Study. Behav Med. 2019;45(4):314-22.

33. Benotsch EG, Seeley S, Mikytuck JJ, Pinkerton SD, Nettles CD, Ragsdale K. Substance use, medications for sexual facilitation, and sexual risk behavior among traveling men who have sex with 
34. Austin EL, Bozick R. Sexual orientation, partnership formation, and substance use in the transition to adulthood. J Youth Adolesc. 2012;41(2):167-78.

35. Yu MH, Guo CM, Gong H, Li Y, Li CP, Liu Y, Guo M, Zhao YQ, Xu J, Li Z, et al. Using latent class analysis to identify money boys at highest risk of HIV infection. Public Health. 2019;177:57-65.

36. Togari T, Inoue Y, Takaku Y, Abe S, Hosokawa R, Itagaki T, Yoshizawa S, Oki S, Katakura N, Yamauchi A, et al. Recreational drug use and related social factors among HIV-positive men in Japan. AIDS care. 2016;28(7):932-40.

37. Feinstein BA, Moran KO, Newcomb ME, Mustanski B. Differences in HIV Risk Behaviors Between SelfIdentified Gay and Bisexual Young Men Who are HIV-Negative. Arch Sex Behav. 2019;48(1):261-75.

38. Guo C, Yu M, Deng X, Gong H, Li Y, Li C, Liu Y, Guo M, Gong X, Feng S, et al. The characteristics of internet-based venue sex-seeking and mobility among money boys in Tianjin, China. HIV Med. 2019;20(7):473-84.

39. Bien CH, Best JM, Muessig KE, Wei C, Han L, Tucker JD. Gay Apps for Seeking Sex Partners in China: Implications for MSM Sexual Health. AIDS Behav. 2015;19(6):941-6.

40. Lehmiller JJ, loerger M. Social networking smartphone applications and sexual health outcomes among men who have sex with men. PloS one. 2014;9(1):e86603.

41. Grosskopf NA, LeVasseur MT, Glaser DB. Use of the Internet and mobile-based "apps" for sex-seeking among men who have sex with men in New York City. Am J Mens Health. 2014;8(6):510-20.

42. Lin CA, Roy D, Dam L, Coman EN. College students and HIV testing: cognitive, emotional self-efficacy, motivational and communication factors. J Commun Healthc. 2017;10(4):250-9.

43. Ju LH, Lyu P, Xu P, Chen WY, He HJ, Ma LP. Features and influencing factors of self-discrimination among HIV/AIDS patients according to sex. Chin J Prev Med. 2016;50(10):863-8.

44. Daskalopoulou M, Rodger A, Phillips AN, Sherr L, Speakman A, Collins S, Elford J, Johnson MA, Gilson $\mathrm{R}$, Fisher $\mathrm{M}$, et al. Recreational drug use, polydrug use, and sexual behaviour in HIV-diagnosed men who have sex with men in the UK: results from the cross-sectional ASTRA study. Lancet HIV. 2014;1(1):e22-31. 